\title{
TOWARDS HEALTHY URBAN DESIGN IN A RATIONALIST NEIGHBOURHOOD: A RESEARCH METHODOLOGY FOR THE MONTICELLI QUARTER IN ASCOLI PICENO, ITALY
}

\author{
CHIARA CAMAIONI, ROSALBA D'ONOFRIO, ILARIA ODOGUARDI \& ELIO TRUSIANI \\ University of Camerino, School of Architecture and Design, Italy
}

\begin{abstract}
In 2012 the WHO's Lancet Commission made a study of potential and innovative associations among the themes of health, social equality, and economic development in urban planning. While recognizing the so-called "urban advantage" for health, the study affirmed that this advantage is not absolute, but is supported by long-term policies and good planning of the urban environment, with a concentration on projects on different scales that involve both the communities and different institutional levels. Some cities have accepted this challenge, trying to build a method to design/regenerate the city, placing health at the centre and involving local populations, various interest holders, and experts. Ongoing experimentation currently concentrates on two themes: methods of evaluating the state of health of cities and quarters and the identification of design proposals consistent with the objectives of health and well-being, which, based on the assessment process, can be improved and made more efficient. This contribution proposes a proper methodology for project assessment, currently in the first phase of experimentation, in the rationalist quarter of Monticelli in Ascoli Piceno (Italy). It is supported by some reference experimentation, including "GO! Utrecht" from the Netherlands National Institute for Public Health and the Environment, the Healthy Urban planning check list from the London Plan 2016, and some experiences developed by the City of New York (Active Design Guidelines, etc.).

Keywords: healthy urban planning and design, healthy neighbourhoods, healthy urban profile.
\end{abstract}

\section{INTRODUCTION}

“...Dimmi dove vivi e saprai quanto a lungo vivrai" [Tell me where you live and you'll know how long you'll live]. This journalistic phrase was used to summarize the contents of a book entitled 40 anni di salute a Torino [Forty Years of Health in Turin] by Prof. Giuseppe Costa, in which the evolution in the health of city inhabitants from the 1970s to today is described in order to demonstrate how economic and social conditions have influenced the life of Turin's residents [1]. The study unfolds as if ideally travelling on line no. 3 of the public transport system, which connects Turin's hill with the northern periphery. Each kilometre travelled within the different quarters of the city corresponds to five fewer years of life. Even if the lifespan of people in Turn has increased over time and the difference between the richest and poorest quarters has decreased, there continue to be substantial differences. These are due to the different economic conditions among the quarters, the services available, and other characteristic components such as road safety, urban structure, social mixité, etc. The study provides further confirmation of what scientific research has been highlighting for at least twenty years: the characteristics of urban quarters influence the behaviour of individuals and their state of health [2]. It is necessary to intervene quickly because current policies for the transformation of land use and transport are having negative effects on people, mainly due to road accidents, atmospheric pollution, and physical inactivity [3]. An estimate made by the WHO (World Health Organization) showed that about $24 \%$ of illnesses and $23 \%$ of deaths worldwide can be attributed to modifiable environmental factors (estimates that drop to $16 \%$ and $20 \%$, respectively, in Europe) [4]. However, it is still not clear to what degree these 
factors contribute to the load of sickness or health of individuals, since a quantitative justification for this relationship has still not been demonstrated.

Despite the existence of this gap, scientific research has for some years supported the real possibility of reducing non-transmissible illnesses using the design of urban spaces, singling out urban planning and design in particular [5]. These are referred to when building healthy, attractive, safe cities and quarters. This call regards both the regional planning scale intervening on factors such as destination, accessibility, distribution of employment, and demand of management - and the local planning scale and local urban design - working on design, density, distance to public transport, diversity and desirability of the spaces [6].

On the local scale, health is a dimension of the quality of life that can and should be improved and reinforced by the close network of relationships between space and everyday life that specifically characterize each quarter of the city [7]. The interpretation and assessment of these relationships play a fundamental role not only in identifying the performance that should necessarily be guaranteed in the design of living spaces, but also in expanding the attention of design from "how to intervene" to "why intervene". It is necessary, that is, to consider the real question that determines the particular needs of construction and management of the urban spaces [8].

In this article, some international experiences on the neighbourhood scale are used to address two themes that are fundamental in renewing the link between the issues of health and urban planning and design.

The first theme regards the means of evaluating the state of health of a quarter to identify in the current state and among the choices of the plan and urban project the presence of potential risks for health. The second theme regards the step from preliminary screening activities to the plan and project, which means also suggesting modifications to the design proposals to make them more coherent with the objectives of health and well-being. The scope is to define an analysis, assessment, and design methodology applied to a concrete case, the Monticelli quarter in Ascoli Piceno (Italy), which can also be replicated in other contexts.

\section{INTERPRETATION AND ASSESSMENT OF THE STATE OF HEALTH OF A QUARTER'S RESIDENTS}

In a 2010 article in the Annals of the New York Academy of Sciences [9], the authors identify two main periods of research in interpreting and assessing the health of inhabitants in a city. The first, starting in the 1980s and 1990s, is based on multi-level epidemiological studies, especially in England and the United States, that used census data and investigations focused on families. These studies were often criticized because they were viewed as lacking a theoretical or methodological basis [10]. In recent years, a second generation of studies has shown greater attention to building a theoretical model capable of relating specific neighbourhood attributes and specific health-related processes and outcomes with reference to two main aspects that may be relevant to health: features of the neighbourhood physical environment and features of the neighbourhood social environment. In this evolution in research, the physical environmental includes not only traditional environmental exposures such as atmospheric pollution, but also other aspects of the built environment, including land use and transport, the design of streets and public spaces, and accessibility to resources such as healthy food and recreational opportunities. In contrast, the social environment includes the degree and nature of social connections among neighbours, the presence of social rules, the level of safety, and various other components of the social sphere.

With regard to the second period of research, New York has developed its Community Health Profiles 2015-2019, with the task of investigating the state of health of 59 districts in 
the city. In addition to demographic indicators and traditional health indicators such as those related to health assistance or people's physical health (life expectation, infant mortality, frequent illnesses, etc.), indicators related to air quality, the number of tobacco sellers, supermarket square footage, the social and economic conditions of families and individuals, and healthy living (self-reported health, sugary drink consumption, physical activity, obesity, diabetes, etc.) were also considered [11].

The community health profiles provide valuable information that can serve as a critical resource for improving health community by community, constituting a step towards participatory public health. These serve as a reference for initiatives that the municipality is implementing to improve the health of New Yorkers, such as the NYC Plaza Program, for example, which is addressed below.

Participation as a method to improve health in neighbourhoods is an approach seen in various countries with different methods (focus groups, charrettes, interviews, web sites, etc.), in addition to traditional methods of information processing in matters of health. The "Go! Utrecht" research project moves in this direction. Realized by RIVM (National Institute for Public Health and the Environment) on behalf of the City of Utrecht (Netherlands) between 2016 and 2017 [12], this research project is organized into four parts:

- An analysis of the data available from the City of Utrecht on the living environment and health of neighbourhood residents, including the creation of integrated district profiles based on 18 indicators selected from among the 51 identified;

- Interviews with residents active in the quarter (one focus group per quarter) to provide an idea of how the residents themselves evaluate their living environment, if they recognize the validity of statistical data, and if they see opportunities for improvement. Seven focus groups were organized with the aim of involving between 5 and 10 residents each;

- Selection of 4-6 "promising" topics per quarter, combining the neighbourhood profiles, interviews, and knowledge/experience of the RIVM's group of experts.

For each quarter, the focus concentrated on indicators that had received a less favourable score than the citywide average. These indicators were then combined with the opinions and experience that emerged from the focus groups and the interaction with experts. The result was a selection of the most "promising" topics (Table 1) in which possible advantages in health could be obtained through a combination of different environmental actions.

- Identification of measures to promote healthy living environments and the combination of different measures to satisfy the topics selected for each quarter. Through bibliographic research and interaction with experts, as many environmental measures as possible were identified and a framework for evaluation for their selection was developed. Combinations of measures were therefore made to offer greater possibilities of obtaining benefits for health than for each individual measure. In addition to experts, focus groups also participated in choosing possible combinations.

At the end of June 2017, ten information sheets were compiled for the ten districts in Utrecht, which summarize the information gathered for each district.

In the case of the "Oost" quarter (Fig. 1), the "promising" topics were identified as: 1. An accessible, clean neighbourhood; 2 . Less traffic; 3 . Increasingly attractive green areas; and 4. Clean air and quiet environment. The measures identified, for example for the second topic, 
Table 1: “Promising Topics” per quarter. (Source: Go! Utrecht (RIVM, 2017).)

\begin{tabular}{|c|c|}
\hline Quarter of Utrecht & Promising Topic \\
\hline South-West & $\begin{array}{l}\text { An attractive, clean neighbourhood } \\
\text { Other trips on bike and on foot } \\
\text { A safe neighbourhood } \\
\text { Living together in the quarter } \\
\text { Increasingly attractive green areas } \\
\text { Movement in green areas }\end{array}$ \\
\hline North-East & $\begin{array}{l}\text { Clean air and quiet environment } \\
\text { An attractive, clean neighbourhood } \\
\text { Working together in the neighbourhood } \\
\text { Increasingly varied green areas } \\
\text { Movement in green areas }\end{array}$ \\
\hline City centre & $\begin{array}{l}\text { Peace and tranquillity in a lively neighbourhood } \\
\text { Clean air and less traffic } \\
\text { Living together in the quarter } \\
\text { Increasingly varied green areas }\end{array}$ \\
\hline Tenente-Meerna & $\begin{array}{l}\text { Increasingly varied green areas } \\
\text { Other trips on bike and on foot } \\
\text { Living together in the quarter } \\
\text { Clean air and quiet environment } \\
\text { Investing in youths and in their neighbourhoods }\end{array}$ \\
\hline Leidsche Rijn & $\begin{array}{l}\text { More accessible structures } \\
\text { Living together in the quarter } \\
\text { Going to school on bike and on foot } \\
\text { An invigorating neighbourhood } \\
\text { Working together in green areas }\end{array}$ \\
\hline East & $\begin{array}{l}\text { An accessible, clean neighbourhood } \\
\text { Less traffic in surrounding areas } \\
\text { Increasingly attractive green areas } \\
\text { Clean air and quiet environment }\end{array}$ \\
\hline West & $\begin{array}{l}\text { Working together in the neighbourhood } \\
\text { Less traffic in surrounding areas } \\
\text { Clean air and quiet environment } \\
\text { Other connections between green areas } \\
\text { A safe neighbourhood }\end{array}$ \\
\hline North-West & $\begin{array}{l}\text { A clean, safe neighbourhood } \\
\text { Other services for residents } \\
\text { Safe traffic } \\
\text { Increasingly varied green areas } \\
\text { Investing in youths and children in their neighbourhoods }\end{array}$ \\
\hline South & $\begin{array}{l}\text { Clean air and quiet environment } \\
\text { More structures and living together in the quarter } \\
\text { Increasingly varied green areas } \\
\text { A clean, safe neighbourhood }\end{array}$ \\
\hline
\end{tabular}


Table 1: Continued.

\begin{tabular}{|l|l|}
\hline Quarter of Utrecht & Promising Topic \\
\hline Overvecht & $\begin{array}{l}\text { Healthy today and in the future } \\
\text { A clean, safe neighbourhood } \\
\text { Living together in the quarter } \\
\text { Safer traffic }\end{array}$ \\
\hline Utrecht as a whole & $\begin{array}{l}\text { More trips on bike and on foot } \\
\text { Increasingly varied green areas } \\
\text { Clean air and quiet environment } \\
\text { Living and working together in the quarter } \\
\text { Healthy food } \\
\text { Moving, playing, and doing sports in the neighbourhood }\end{array}$ \\
\hline
\end{tabular}

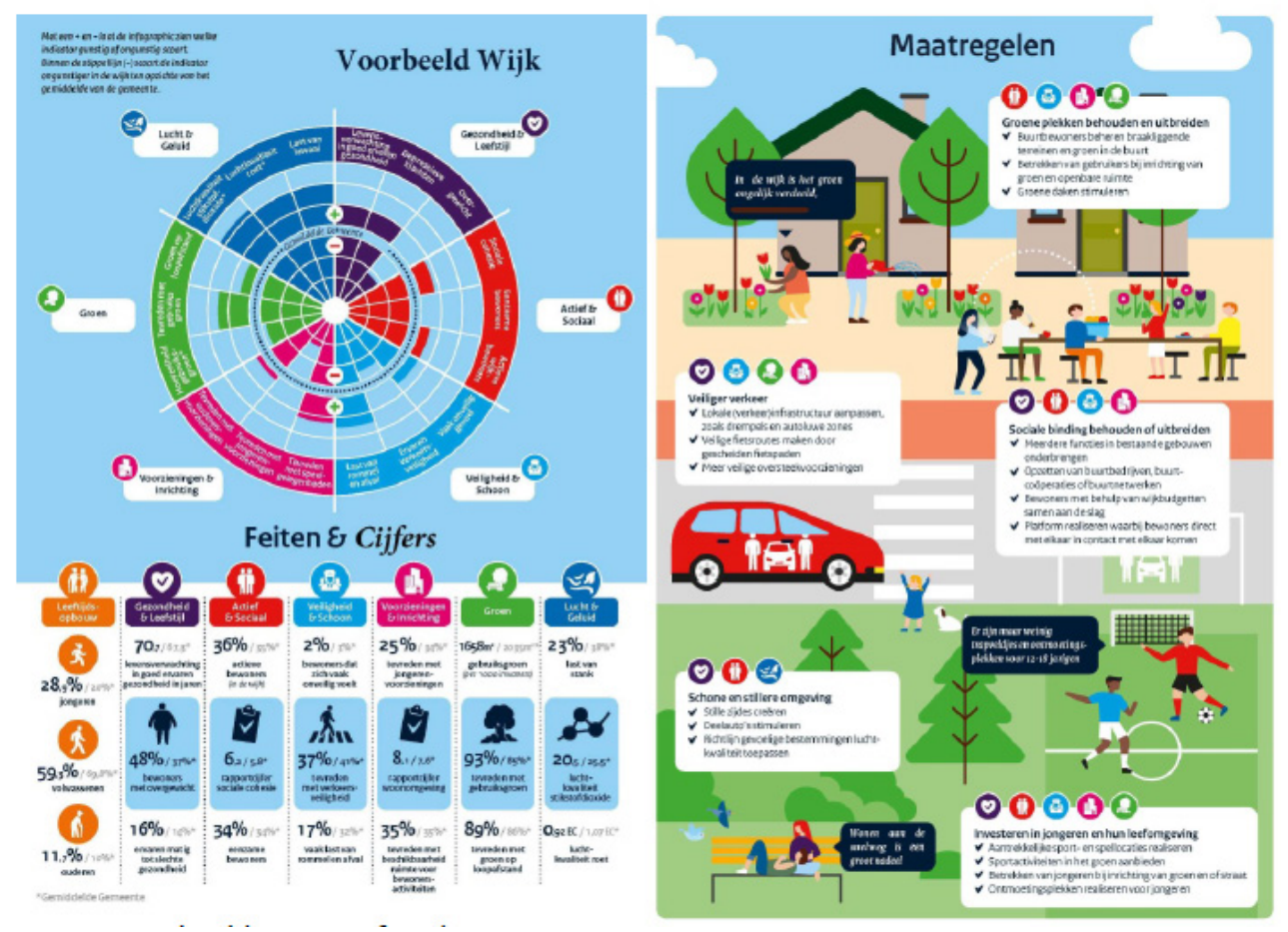

Figure 1: Sheet for the "Oost" quarter - topic/measure combination. (Source: Go! Utrecht (RIVM, 2017).)

were: further increasing parking for bicycles; control of streets by residents; working to improve one's own street; encouraging the use of carpooling; and greater traffic monitoring.

It should be noted that in this case, the effects on health of the combination of measures adopted in the physical and social environment are mainly based on a qualitative estimate and the results of the research were translated into action perspectives for a healthier 
environment of life for the city. It is expected that the measures identified can contribute to realizing the objective declared by the city: "Promote a healthy living environment for all Utrecht residents" to pursue in all urban policies in the coming years. Recognition of the costs and benefits of the measures proposed is lacking because they were not deemed necessary for the goals of the research.

\section{HEALTHY URBAN PLANNING AND DESIGN}

Healthy urban planning was one of the three focus areas of Phase IV of the WHO's European Healthy Cities network. The objective was to integrate health policies in urban plans and projects and to request a political and institutional commitment to reaching this objective. The City of London was one of the first to follow this route, even seizing opportunities tied to the important legislative and social reforms that have been promoted in recent years in terms of health and urban planning in the National Planning Policy Framework (NPPF) from 2012, the Health and Social Care Act of 2012, the Localism Act 2011. Furthermore, Policy 3.2 of London Plan 2016, requires that urban transformations be designed, built, and managed such that they improve health and promote healthy lifestyles in order to contribute to reducing health inequalities. The plan makes use of the "healthy urban-planning checklist" [13], which was originally developed in 2012 to assess plans and projects for the six Olympic and Paralympic quarters. The objective is to promote a collaborative approach and encourage the different interested parties (health authorities, health organizations, urban planners, local communities) to collaborate in addressing the health impacts of the proposals to transform the city. The checklist can be used by:

- Developers to examine and assess the health impacts of development proposals;

- Those responsible for planning, to help to identify and address the health impacts of development proposals;

- Professionals in public and environmental health, to comment on and examine plans and proposals for development;

- Neighbourhood forums, community groups, and citizen associations, to comment on planning proposals and to favour the community's commitment.

The control list is divided into four areas: healthy housing; active travel; healthy environment; and vibrant neighbourhoods. Each area refers to a series of questions centred on a planning problem. For the "healthy housing" area, the planning issues are, for example: housing design; accessible housing; healthy living; housing mix; and affordability. With reference to each theme, a series of issues related to health and well-being are also highlighted, many of which are identified in local joint strategic needs assessments and health and well-being strategies, such as those related to:

- Obesity and illnesses tied to physical inactivity and poor diet;

- Abnormally high mortality in the winter;

- Atmospheric and noise pollution;

- Road safety;

- Social segregation.

Each planning issue is also connected to requirements and legal standards and related to its effects on health. The objective is that each proposal for development compared with the checklist reaches the highest possible number of "yeses", avoiding the "noes". Very briefly, the checklist acts as a stimulus for discussion and negotiation in local urban planning, 
supported by internal and external consultations that involve different responsibilities and rest on supporting information.

Urban planning that focuses on health and well-being should try to free itself from risks attributed to the effects of planning choices such as: atmospheric pollution, road accidents, the lack of green areas and services, and poor housing quality. It should also use "active design" practices capable of responding to the increasingly pressing demand to improve the quality of building design, roads, and urban spaces to improve the quality of life in cities.

In the search for a renewed dimension of urban design that is open to comparison and local community participation, other experiences aside from London suggest referring to directory documents that the design proposals can refer to without the pretext of becoming cogent rules, but useful for interacting with the local communities and stakeholders. One of these is New York City, with its Active Design Guidelines [14].

This guide grew out of collaboration in 2006 between the Department of Health and Mental Hygiene and the American Institute of Architects New York Chapter (AIANY), accompanied by other detailed documents. It proposes providing architects and urban planners with a manual of strategies to create healthier buildings, roads, and urban spaces based on the latest academic research and best practices in the sector.

It constitutes the reference for urban plans and projects, with the objective of:

- Developing and maintaining mixed land use in city neighbourhoods;

- Improving access to transit and transit facilities;

- Improving access to plazas, parks, open spaces, and recreational facilities, and designing these spaces to maximize their active use where appropriate;

- Improving access to full-service grocery stores and fresh produce;

- Designing accessible, pedestrian-friendly streets with high connectivity, trafficcalming features, landscaping, lighting, benches, and water fountains;

- Facilitating bicycling for recreation and transportation by developing continuous bicycle networks and incorporating infrastructure like safe indoor and outdoor bicycle parking.

But these guidelines are not an isolated response to city planning; there are many programs and projects that have implemented inspiring principles. Over time, the Department of Transportation's (DOT) Plaza Program, for example, launched in 2008, has financed a series of pedestrian squares throughout the city, converting unused areas or changing the traffic models [15]. This project was supported by studies that demonstrated that people need to live within 10 minutes from a park or open space to be able to use it regularly. Through a competition that is opened every year, the numerous community non-profit organizations present in the city can apply to create squares in their neighbourhoods. After examining and assessing the applications, the DOT chooses a square and works with the selected organizations (partners) to establish a vision and an appropriate program for each plaza.

One of these interventions, shown in Fig. 2, saw the transformation of a service street into a pedestrian space called "Corona Plaza", first by building a temporary square and then beginning a long reconstruction process with the support of the Queens Economic Development Corporation and the local community.

\section{WORK PROPOSED FOR THE MONTICELLI QUARTER IN ASCOLI PICENO, ITALY}

The case studies described in this article, together with others that were investigated in Urban Planning for Healthy European Cities [16], allowed for the construction of a working 

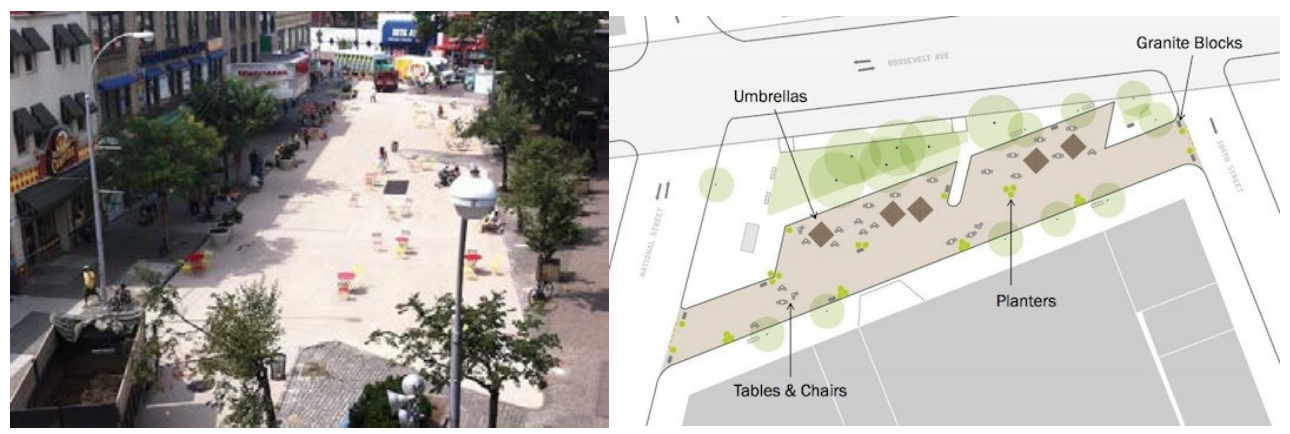

Figure 2: Corona Plaza after the transformation. (Source: StreetBlogNYC.)

method, with reference to the two themes that were deemed crucial in the Introduction The evaluation about profile of a neighbourhood and the step from the preliminary screening activity to a proposal to transform the physical spaces of the quarters, focusing on inhabitants' health and quality of life.

A practical case was addressed: a quarter in the City of Ascoli Piceno (Italy) - Monticelli - with the idea of preparing a working methodology that can also be exported to other quarters in the city and to other cities.

The Monticelli quarter is one of the most populous in the city of Ascoli Piceno, with about 10,000 inhabitants. It is located only a few kilometres from the historical centre, but " ... you can't get to Monticelli on foot", as the local news reported a few years ago. Until the beginning of the 1970s, the land where the quarter is located was practically open country. In 1972, the city was endowed with its first local plan. This called for linear development along the east-west expanse of the city and defined a broad area to the east of the city (Monticelli) where the greatest residential volumes, built new, would be concentrated, in order to house 21,600 inhabitants (compared to the roughly 75,000 inhabitants expected in the entire municipal territory for the year 1975). It was quickly realized that the forecast for an increase in population from 50,000 to about 75,000 inhabitants was entirely unlikely, and that the nucleus of expansion in Monticelli was oversized in relation to the effective demographic trends. Despite this, the city administration proceeded to partially realize the housing and main roads as established by the plan. This was done in consideration of the fact that the earthquake of 1972 had caused serious damage to the building heritage in the historical centre, with the consequent abandonment of uninhabitable buildings and the fact that the zones for social housing in Monticelli could take advantage of significant economic subsidies. Today, the quarter contains the hospital, a supermarket, offices, various types of shops, two churches, and, until a short time ago, a fast-food restaurant (Fig. 3).

For most of Ascoli Piceno's residents, Monticelli is simply a dormitory, a quarter situated between a road axis and the Tronto River, a small town in and of itself with respect to the rest of the city of Ascoli Piceno. The quarter lacks infrastructure and equipped green areas, it lacks meeting points and places that identify the quarter, and some residential buildings are degraded. The city news reports stories of drug addiction, aggression, and accidents due to dangerous cross traffic - both on the central axis and the internal streets - smog, and noise. Despite this, there are signs of liveliness and action by the local population in the presence of sports associations, social gardens, and a very busy senior centre. Attention for the quarter has re-emerged in recent years following urban regeneration projects financed with national public funds and local interest holders, such as the Neighbourhood Contract 2 - Extraordinary 


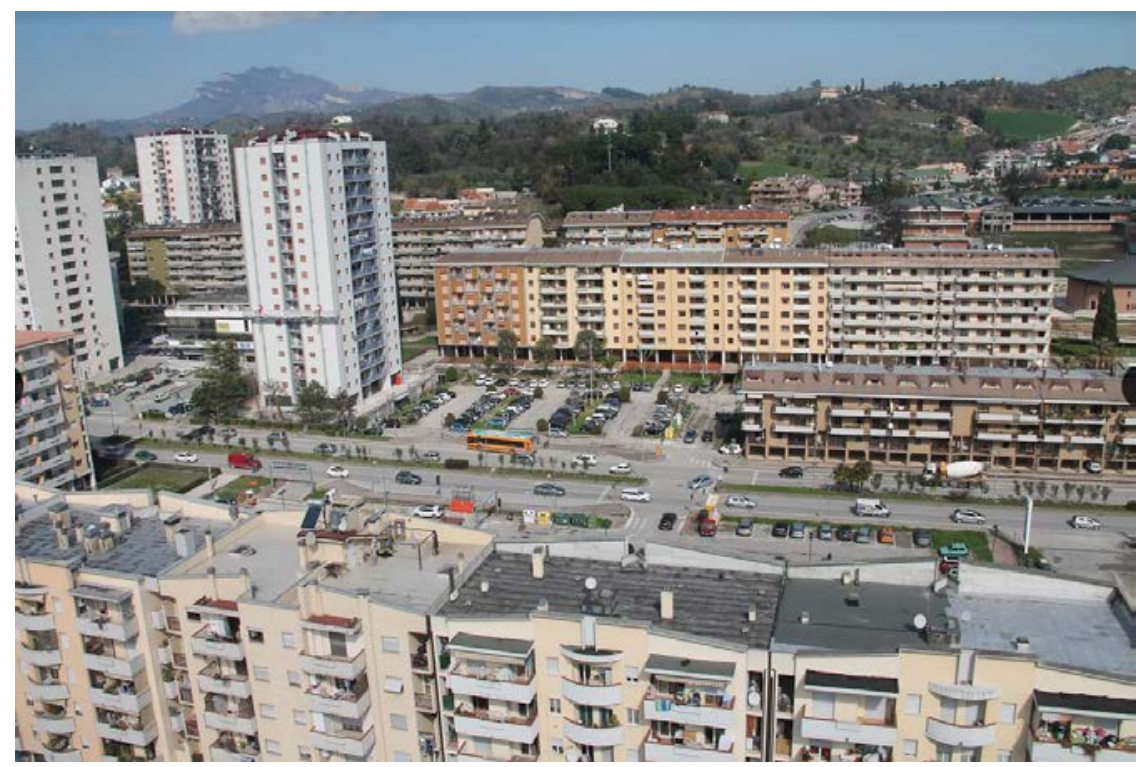

Figure 3: View of the central road axis. (Source: Authors, 2015.)

Programme for Peripheries (Contratto di Quartiere 2- il Programma Straordinario per le Periferie-PRASI), which establishes a budget of $€ 86$ million, of which $€ 18$ million is financed by the State with some interventions on the roads, green areas, and degraded buildings.

The research program "Healthy Monticelli", begun at the end of 2017, was anticipated by the "Urban planning laboratory" that was held in 2015 and saw the participation of students from the School of Architecture and Design at the University of Camerino, which activated a project in the quarter to interpret the city based on a collaborative mapping platform. The interactive FURIAMAP was constructed by the students with input from inhabitants in the quarter. About 40 students were divided into 8 working groups on 8 topics of investigation use of spaces, landmarks, heroes, citizens, memory, image, safety, lights-sounds-colours. They gathered interviews, videos, photographs, and animated a map accessible at Cityopensource.net.

"Healthy Monticelli" was begun based on what emerged from this map, statistical and cartographic investigations. It involves the participation of the Healthy City research group at UNICAM, the City of Ascoli Piceno, the local health agency (ASUR), and a research centre and some external researchers. The research proposal is to construct a possible working methodology for the urban regeneration of problematic quarters, centring on the health and well-being of inhabitants and using the quarter of Monticelli as a first experimental case.

The methodological proposal is organized into five phases, and the research group is currently developing the first phase.

\section{1) Recognition of the quarter's health needs}

In close collaboration with ASUR Area Vasta 5, the PASSI Questionnaire (Progress of Health Services for Health in Italy; Progressi delle Aziende Sanitarie per la Salute in Italia) will be 
administered to the quarter's residents, appropriately refined based on a comparison of the experts present in the research group and the objectives of the research themselves.

Also "Focus Groups" will be created around specific topics identified on the questionnaire, which will be open to citizens and the various interest holders; among them: the perception of the quality of life in the city, safety, and the quality of the air. Others could arise from the interaction between inhabitants and experts.

From the exploratory activity and the comparison, the profile of the population's health and the "key topics" in terms of health and well-being should emerge, on which the research will be concentrated.

This activity is undergoing implementation in collaboration with UNICAM, ASUR, and external experts.

The expected results of this first phase are: a) the health profile for the Monticelli quarter; b) identification of the "key topics" of health in Monticelli.

\section{2) Comparison of the results of the scientific research and the health needs for the Monticelli} quarter

Identification of the lines of scientific relationships that have investigated the relationships between the "key topics" selected by the focus groups and the health profile that emerged in the first phase; identification of the most important topics in urban planning and urban design for Monticelli; and identification of the performance of spaces in the city to be guaranteed in terms of health and well-being.

The expected results of this second phase are:

a) A database of the scientific research that supports the relationships between health, wellbeing, and design of the urban environment;

b) Selection of the "topics" of urban planning and urban design to investigate that emerged from the first phase and were addressed by the scientific research selected. These include land use, mobility, housing, access to food, open spaces and meeting spaces, and the natural environment;

c) Construction of matrix of the relationships and the performance needs of the quarter in terms of health and well-being with reference to the health needs identified, the topics of urban planning and urban design investigated, and the validation that emerged based on the scientific research selected.

\section{3) Assessment of the health performance of the Monticelli quarter}

In reference to the instances of health and well-being emerging from the Health Profile and the database of scientific research, a checklist will be created to assess:

- The current state of the quarter;

- Design forecasts in the "peripheral plan";

The expected results of this phase are:

a) Specifics of the quarter's performance in reference to the needs of health and well-being: critical and positive aspects.

\section{4) Identification of actions to implement in order to design "Healthy Monticelli"}

Identification of measures to implement in order to solve the critical points emerging from the third phase, the current state, from projects planned or in progress (Peripheral Plan), with the support of an outline of international best practices organized by recurring theme.

The expected results of this second phase are: 
a) List of actions and combinations of actions to implement to design Monticelli, along with their performance framework.

\section{5) Healthy Monticelli: from urban planning to urban design}

Construction of a database on the experiences in "Guidelines for Healthy urban planning and design" developed by the various international experiences; identification of possible design alternatives/integrations for Monticelli.

The expected results of this second phase are:

a) Database of best practices; b) guidelines for design.

\section{CONCLUSION}

One knot to untangle in regenerating the contemporary city regards the effective possibility for the city to recover the skills of profiling, assessment, and negotiation in order to respond to the social demand for citizens' quality of life. With reference to urban-planning and design tools, affirming the centrality of the themes of the well-being and health of local communities constitutes a powerful call to overcome the quantitative approach and embrace the performance approach in city design. With the contribution of some important international experiences, the methodology proposed with Healthy Monticelli represents an attempt to build a means of assessment and design on the quarter scale, with the twofold goal of:

- Selecting themes on which the urban plan and project should concentrate to respond to the needs for community health and to address the risks that threaten the quality of life in cities;

- Identifying a combination of actions to implement to resolve criticalities and to suggest design proposals that are more consistent with the objectives of health and well-being.

The approach proposed calls for the integration of social policies and health policies, but also environmental and living policies in a vision of health in which the living conditions and the well-being of citizens are the result of the action of an entire community.

\section{REFERENCES}

[1] Costa, G., Stroscia, M., Zengarini, N. \& Demaria, M., 40 anni di salute a Torino. Spunti per leggere i bisogni e i risultati delle politiche, Inferenze: Milan, 2017.

[2] O’Campo, P., Wheeton, B., Nisenbaum, R., Glazier, R.H., Dunn, J.R., Chambers, C., The neighbourhood effects on health and well-being (NEHW) study. Health \& Place, 31, pp. 65-74, 2015.

[3] Woodcock, J. et al., Public health benefits of strategies to reduce greenhouse-gas emissions: Urban land transport. Lancet, 374, pp. 1930-1943, 2009.

[4] Prüss-Üstün, A., Corvalán, C.F. \& World Health Organization, Preventing disease through healthy environments: Towards an estimate of the environmental burden of disease: Executive summary/Prüss-Üstün A, Corvalán C. Geneva: World Health Organization. Online. www.who.int/iris/handle/10665/43375, 2006.

[5] Rydin, Y., Bleahu, A., Davies, M., Dávila, J.D., Friel, S., De Grandis, G., Lai, K.M., Shaping cities for health: Complexity and the planning of urban environments in the 21 st century. The Lancet, 379(9831), pp. 2079-2108, 2012. DOI: 10.1016/s01406736(12)60435-8. 
[6] Giles-Corti, B., Vernez-Moudon, A., Reis, R., Turrell, G., Dannenberg, A.L, Badland, H., Foster, S., Melanie Lowe, J., Sallis, J.F., Stevenson, M. \& Owen, N., City planning and population health: A global challenge. Lancet, 388, pp. 2912-2924, 2016.

[7] Borlini, B. \& Memo, F., Il quartiere nella città contemporanea, Mondadori Bruno: Milan, 2008.

[8] D’Onofrio, R. \& Trusiani, E., Città, salute e benessere. Nuovi percorsi per l'urbanistica, F. Angeli: Milan, 2017.

[9] Dies Roux, A.V. \& Mair, C., Neighborhoods and Health, Academy of Sciences: New York, 2010.

[10] O'Campo, P., Invited commentary: Advancing theory and methods for multilevel models of residential neighborhoods and health. American Journal of Epidemiology, 157(1), pp. 9-13, 2003. DOI: 10.1093/aje/kwf171.

[11] NYC Health, New York City Community Health Profiles. Online. www1.nyc.gov/site/doh/data/data-publications/profiles.page, 2015.

[12] RIVM, RIVM Briefrapport 2017-0189. Gezonde Omgeving Utrecht (GO! Utrecht) Handelings. Online. www.rivm.nl/Documenten_en_publicaties/Wetenschappelijk/ Rapporten/2018/Januari/Gezonde_Omgeving_Utrecht_GO_Utrecht_Handelingspers pectieven_voor_een_gezonde_leefomgeving, 2017.

[13] NHS London Healthy Urban Development Unit, Healthy Urban Planning Checklist. Online. www.healthyurbandevelopment.nhs.uk/.../Healthy-Urban, 2016.

[14] NYC, The Active Design Guidelines. Online. https://centerforactivedesign.org/ guidelines/, 2010.

[15] NYC, Pedestrians NYC Plaza Program. Online. www.nyc.gov/html/dot/html/ pedestrians/nyc-plaza-program.shtml, 2008.

[16] D'Onofrio, R. \& Trusiani, E., Urban Planning for Healthy European Cities, Springer Verlag, 2018. 